\title{
NGHIÊN CỬU ẢNH HƯởNG CỦA CHẾ ĐỘ SỤC KHÍ ĐẾN HIỆU QUẢ XỬ LÝ COD, NITO TRONG NƯỚC THẢI CHĂN NUÔI LỘN SAU XỦ LÝ YẾM KHÍ BẰNG PHƯƠNG PHÁP LỌC SINH HỌC NGẬP NƯỚC
}

\section{Study on effects of aeration mode on Cod and Nitrogen treatment efficiency in waste water from pig livestock after anaeration treatment by submerged biofilter recirculation method}

ThS. Đặng Thị Hồng Phương*

\section{TÓM TẮT}

Mục đích của nghiên cứu này là lựa chọn chế độ sục khí thích hợp nhất để vận hành hệ thống lọc sinh học ngập nước trong việc xử lý nước thải chăn nuôi lợn sau xử lý yếm khí. Kết quả nghiên cứu cho thấy, chế độ sục khí không ảnh hưởng nhiều đến hiệu quả xử lý COD. Hiệu quả xử lý COD ở cả 3 chế độ sục khí đạt trong khoảng 80 - 85\% và khá ổn định. COD đầu ra hầu hết dao động khoảng $200 \mathrm{mg} / \mathrm{L}$. Hiệu suất loại bỏ Nitơ ở chế độ 1 (sục khí - ngừng sục khí là 60 phút/90 phút) chỉ đạt khoảng 60 - 65\%, chế độ 2 (sục khí - ngừng sục khí là 90 phút/90 phút) thời gian hiếu khí được tăng lên và hiệu suất loại bỏ $\mathrm{N}$ đạt cao hơn khoảng $65-70 \%$. Hiệu suất xử lý $\mathrm{N}$ đạt cao nhất ở chế độ 3 (sục khí - ngừng sục khí là 110 phút/70 phút) đạt khoảng $75-80 \%$. Các thí nghiệm nhằm nghiên cứu ảnh hưởng của tải lượng $\mathrm{COD}, \mathrm{T}-\mathrm{N}$ hiệu suất xử lý nước thải cho thấy, tải lượng $\mathrm{COD}, \mathrm{T}-\mathrm{N}$ ảnh hưởng nhiều đến hiệu suất xử lý $\mathrm{T}-\mathrm{N}$ trong nước thải chăn nuôi lợn. Chế độ $2(\mathrm{Q}=19,2 \mathrm{~L} /$ ngày, thời gian lưu là 2 ngày), tải lượng $\mathrm{T}-\mathrm{N}$ duy trì trong khoảng 0,14 - $0,21 \mathrm{~kg} / \mathrm{m}^{3} /$ ngày, hiệu suất đã được nâng lên ở khoảng $70-80 \%$. Đây chế độ thí nghiệm cho hiệu suất xử lý T-N cao nhất.

Từ khóa: COD, chế độ thí nghiệm, lọc sinh học ngập nước, nuớc thải chăn nuôi lợn, sục khí.

\begin{abstract}
The main aim of this study is to select an appropriate aeration mode for operating the submerged biofilter system to treat waste water from pig livestock after anaeration treatment. Results showed that aeration mode did not affect much on COD treatment efficiency. COD was treated well and stably in three aeration modes, reaching $80-85 \%$. Treated COD was about $200 \mathrm{mg} / \mathrm{L}$. Efficiency of Nitrogen removal reached only $60-65 \%$ in the first mode (aeration/unaeration $=60 \mathrm{~min} . / 90 \mathrm{~min}.), 65-70 \%$ in the second mode (aeration/unaeration $=$ 90min./90min.) and maximum of $75-80 \%$ in the third mode (aeration/unaeration = $110 \mathrm{~min} . / 70 \mathrm{~min}$.). The experiments and studies on effects of COD tonnage, T-N efficiency. The result showed that COD, T-N tonnage would affected much on T-N treatment efficiency. In the second mode $(\mathrm{Q}=19.2 \mathrm{~L} /$ day with period of two days), $\mathrm{T}-\mathrm{N}$ tonnage maintained within $0.14-0.21$ $\mathrm{kg} / \mathrm{m}^{3} /$ day, and efficiency increased to $70-80 \%$. This is the most successful mode for treatment of waste water.
\end{abstract}

Keywords: $C O D$, experiment mode, submerged biofilter, Waste water, pig livestock, aeration.

\footnotetext{
*Bộ môn Khoa học \& Công nghệ Môi trường, Khoa Môi trường, Đại học Nông Lâm Thái Nguyên
} 


\section{1. Đặt vấn đề}

Những năm gần đây, với chủ trương mở cửa, thúc đẩy phát triển kinh tế của nước ta, lĩnh vực chăn nuôi đã đạt được rất nhiều tiến bộ. Năm 2009, Việt Nam đã vươn lên đứng thứ 2 Châu Á sau Trung Quốc về sản lượng thịt lợn (Bộ Nông nghiệp và phát triển nông thôn, 2011).

Ở Việt Nam, chăn nuôi lợn được coi là thế mạnh của ngành nông nghiệp, cùng với sự gia tăng dân số, gia tăng các nhu cầu về lương thực, thực phẩm, ngành chăn nuôi càng được đầu tư phát triển mạnh. Trước đây, chúng ta chỉ có chăn nuôi nhỏ lẻ tại các hộ gia đình. Hiện nay, trong bối cảnh thức ăn chăn nuôi, vật tư chăn nuôi đều tăng, cùng với đó là sức cạnh tranh, vấn đề kiểm soát dịch bệnh nên việc chăn nuôi trong các hộ gia đình có xu hướng giảm trong khi chăn nuôi gia trại, trang trại tăng nhanh và tạo được khả năng cạnh tranh trên thị trường (Phùng Thị Vân, et al., 2005). Do vậy, vấn đề chất thải phát sinh từ hoạt động chăn nuôi lợn cần phải được quản lý tốt. Chất thải của các trang trại chăn nuôi lợn với thành phần chủ yếu là phân lợn và nước thải hiện đang là vấn đề lo lắng của các nhà quản lý.

Hầu hết việc xử lý chất thải của các hộ chăn nuôi là lắp đặt hệ thống xử lý chất thải Biogas, nhưng hệ thống này chưa đủ công suất đáp ứng nhu cầu xử lý toàn bộ chất thải mà chỉ đạt được 50\% - 70\% lượng chất thải của trang trại. Tuy nhiên, với nhiều trang trại đã có hầm biogas, có hệ thống xử lý chất thải nhưng chất thải chưa được xử lý triệt để (Vũ Đình Tôn, et al., 2008).

Một trong các quá trình sinh học hiếu thiếu khí kết hợp được nghiên cứu ứng dụng nhiều trong xử lý nước thải chăn nuôi lợn là phương pháp lọc sinh học ngập nước (Lê Công Nhất Phương, 2009). Nghiên cứu này trình bày một số kết quả đạt được khi thay đổi chế độ sục khí đến quá trình xử lý nước thải chăn nuôi lợn sau xử lý yếm khí bằng phương pháp lọc sinh học ngập nước.

\section{2. Đối tượng, nội dung và phương pháp nghiên cứu}

\section{1. Đối tự̆ng và phạm vi nghiên cúu}

- Đối tượng nước thải được chọn là: Nước thải chăn nuôi lợn sau xử lý yếm khí (sau biogas).

- Phạm vi nghiên cứu: Hiệu quả xử lý nước thải chăn nuôi sau xử lý yếm khí bằng phương pháp lọc sinh học ngập nước: Nghiên cứu hiệu quả xử lý $\mathrm{COD}, \mathrm{T}-\mathrm{N}$ trong nước thải chăn nuôi lợn ở các chế độ sục khí/ngừng sục khí khác nhau.

\subsection{Nội dung nghiên cúu}

- Nghiên cứu ảnh hưởng của chu kỳ sục khí - ngưng sục khí đến hiệu suất xử lý COD, T-N.

- Nghiên cứu ảnh hưởng của tải lượng $\mathrm{COD}$, tải lượng T-N đến hiệu suất xử lý $\mathrm{COD}$, T-N.

\subsection{Phương pháp nghiên cúu và chỉ tiêu} theo dõi

a) Phwơng pháp nghiên cúu

- Phương pháp lấy mẫu: Lấy mẫu theo QCVN 4556-88.

- Phương pháp phân tích: Phân tích các chỉ tiêu COD, Amoni, Nitrat, Nitrit, tổng $\mathrm{N}$ theo QCVN hiện hành

- Phương pháp thu thập và xử lý số liệu:

Tiến hành theo dõi hàng ngày và ghi lại các số liệu trong quá trình làm việc, xử lý bằng Excel.

- Phương pháp tính toán: (Lê Văn Khoa, et al., 2002)

+ Tính tải lượng: COD, T-N:

$(39 * 1000)$

$\mathrm{L}=$ Cvào (mg/L) * Qvào (L/ngày)/

+ Tính hiệu suất xử lý: $\mathrm{COD}, \mathrm{NH}_{4}{ }^{+}, \mathrm{T}-\mathrm{N}$ :

$\mathrm{H}=$ (Cvào - Cra)*100/Cvào

+ Tính thời gian lưu: 
$\mathrm{T}=\mathrm{V} /$ Qvào

Trong đó: LCOD, LT-N: Tải lượng COD, $\mathrm{N}\left(\mathrm{kg} / \mathrm{m}^{3} /\right.$ ngày $)$

$\mathrm{T}$ : Thời gian lưu nước thải (ngày),

$\mathrm{V}$ : Thể tích nước trong bể phản ứng $(\mathrm{L})$,

Q: Lưu lượng $(\mathrm{L} / \mathrm{h})$

H: Hiệu suất xử lý (\%)

Cvào: Nồng độ $\mathrm{COD}, \mathrm{NH}_{4}^{+}$hoặc T-N đầu vào $(\mathrm{mg} / \mathrm{L})$.

Cra: Nồng độ COD, $\mathrm{NH}_{4}{ }^{+}$hoặc T-N đầu $\mathrm{ra}(\mathrm{mg} / \mathrm{L})$.

1000: hệ số quy đổi

- Địa điểm thực hiện thí nghiệm: Viện Công nghệ Môi trường, Viện Hàn Lâm Khoa học - Công nghệ Việt Nam, từ tháng 1 đến tháng 5 năm 2014.

- Vật liệu nghiên cứu: Vật liệu mang vi sinh (vật liệu lọc sinh học) sử dụng trong nghiên cứu là loại đệm nhựa có gấp nếp có sẵn trên thị trường có diện tích bề mặt riêng khoảng $200 \mathrm{~m}^{2} / \mathrm{m}^{3}$ và độ rỗng $>95 \%$.

- Vi sinh vật: Vi sinh vật gốc được lấy từ nhà máy bia Việt Hà để rút ngắn thời gian khởi động.

b) Các chế độ thí nghiệm

+ Chế độ 1 (CĐ 1): Chế độ sục khí ngừng sục khí $60 / 90$ phút, thời gian lưu 2 ngày, $\mathrm{Q}=19,2$ L/ngày.

+ Chế độ 2 (CĐ 2): Chế độ sục khí ngừng sục khí 90/90 phút, thời gian lưu 2 ngày, $\mathrm{Q}=19,2$ L/ngày.

+ Chế độ 3 (CĐ 3): Chế độ sục khí ngừng sục khí 110/70 phút, thời gian lưu 2 ngày, Q = 19,2 L/ngày.

(lít/ngày))

(Trong đó: $\mathrm{Q}$ là lưu lượng đầu vào

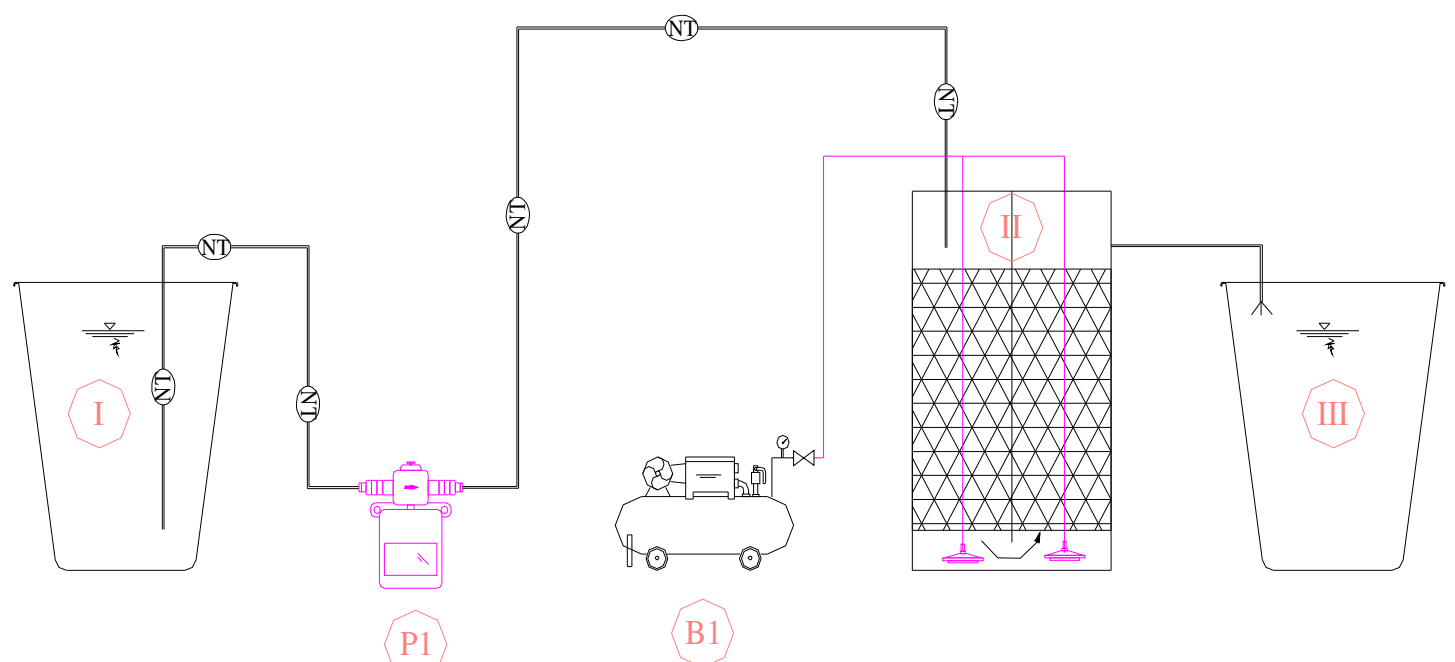

Hình 1. So đồ hệ thiết bị thí nghiệm lọc sinh học ngập nước

\section{c) Mô hình thiết bị thí nghiệm (Hình 1)}

Ghi chú: I: Xô nhựa chứa nước thải đầu vào có chia vạch định mức; P1: Máy bơm nước thải đầu vào; B1: Máy bơm cấp khí; II: Bể phản ứng; III: Xô nhựa chứa nước thải đầu ra

Hệ thiết bị lọc sinh học ngập nước quy mô phòng thí nghiệm làm bằng nhựa $\mathrm{PVC}$ trong suốt. Hệ thí nghiệm có thể tích là 39 lít; gồm hai ngăn, mỗi ngăn có thể tích là 19,5 lít. Công suất thiết kế là 19,2 lít/ngày.

Không khí được sục vào hệ lọc sinh học thông qua hai ống phân phối khí được đặt dưới đáy bể bằng máy thổi khí và có thể điều chỉnh được tốc độ. Các chế độ hoạt động (Thời gian làm việc, ngừng làm việc) của các bơm, máy thổi khí có thể cài 
đặt, thay đổi được và được điều khiển tự động.

Nước từ ngăn thứ hai của bể sinh học tự chảy qua thùng chứa nước sau xử lý qua đường ống được đặt ở phía trên thành ngăn thứ hai của bể sinh học.
Bùn sinh ra trong quá trình xử lý được tháo định kỳ thông qua 2 van xả ở đáy bể.

Chi tiết hệ thiết bị thí nghiệm được thể hiện trong bảng 1 .

\section{Bảng 1. Chi tiết thiết bị thí nghiệm}

\begin{tabular}{|c|l|c|}
\hline TT & \multicolumn{1}{|c|}{ Thiết bị } & Số lượng \\
\hline 1 & Bể lọc sinh học ngập nước & 01 \\
\hline 2 & Xô nhựa chứa nước thải đầu vào và đầu ra & 02 \\
\hline 3 & Bộ điều khiển bằng điện (đồng hồ...) & 1 bộ \\
\hline 4 & Máy bơm nước thải vào & 01 \\
\hline 5 & Máy bơm khí & 01 \\
\hline 6 & Đầu đo DO & 01 \\
\hline
\end{tabular}

\section{Kết quả nghiên cứu và thảo luận}

\section{1. Đặc trung nước thải thí nghiệm}

Nước thải chăn nuôi lợn lấy tại bể biogas của Trung tâm nghiên cứu lợn Thụy Phương thuộc Viện Chăn nuôi (Cổ Nhuế, Hà Nội). Đặc trưng của nước thải trong nghiên cứu được thể hiện trong (bảng 2).
Nước thải chăn nuôi lợn sau xử lý ky khí còn chứa nồng độ chất hữu cơ cao và nitơ cao, cần có các biện pháp xử lý thích hợp tiếp theo để đảm bảo đạt các tiêu chuẩn môi trường.

Bảng 2. Đặc trưng nước thải chăn nuôi lọ̣n sau xử lý kỵ khí

\begin{tabular}{|c|c|c|c|}
\hline STT & Thông số & Đon vị & Hàm lượng \\
\hline 1 & $\mathrm{pH}$ & - & $6,5-8,5$ \\
\hline 2 & $\mathrm{COD}$ & $\mathrm{mg} / \mathrm{L}$ & $1100-1600$ \\
\hline 3 & $\mathrm{~N}^{-N_{4}}{ }^{+}$ & $\mathrm{mg} / \mathrm{L}$ & $350-450$ \\
\hline 4 & $\mathrm{~N}^{-\mathrm{NO}_{3}}{ }^{-}$ & $\mathrm{mg} / \mathrm{L}$ & $0-2,5$ \\
\hline 5 & $\mathrm{Tồng} \mathrm{N}^{2}$ & $\mathrm{mg} / \mathrm{L}$ & $600-800$ \\
\hline 6 & Tổng $\mathrm{P}^{2}$ & $\mathrm{mg} / \mathrm{L}$ & $30-90$ \\
\hline 7 & $\mathrm{TSS}$ & $\mathrm{mg} / \mathrm{L}$ & $700-1600$ \\
\hline
\end{tabular}




\section{2. Ảnh hưởng của chu kỳ sục khí-} ngung sục khí đến hiệu quả xủ lý COD, $N$

\subsubsection{Hiệu quả xủ lý $C O D$}

Hiệu quả xử lý COD tại các chế độ thí nghiệm khác nhau được thể hiện trên hình 2 :

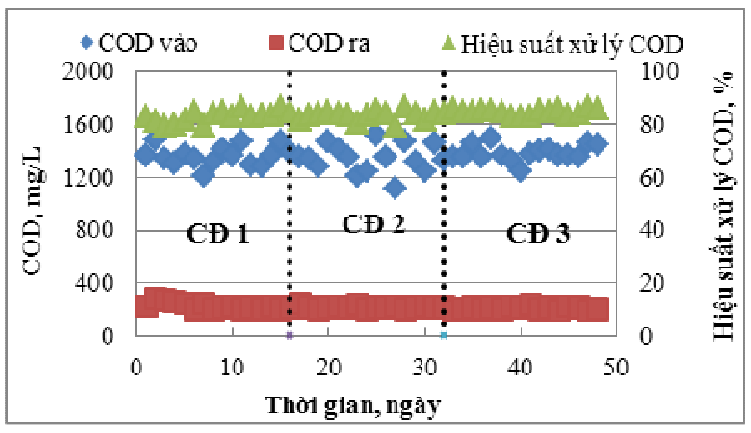

Hình 2. Anh hương của chế độ sục khí/ngìng succ khí đến hiệu suất xử lý COD

- Tại chế độ thí nghiệm 1, chu kỳ sục khí - ngừng sục khí là 60 phút/90 phút, nồng độ COD đầu vào dao động trong khoảng 1200 - 1600 mg/L. Nồng độ đầu ra dao động trong khoảng 200 - $300 \mathrm{mg} / \mathrm{L}$, hiệu suất xử lý COD đạt khoảng 79\% - 85\%.

- Tại chế độ thí nghiệm 2, chu kỳ sục khí - ngừng sục khí là 90 phút/90 phút, nồng độ COD đầu vào dao động trong khoảng 1000 $1500 \mathrm{mg} / \mathrm{L}$. Nồng độ COD đầu ra dao động khoảng $200 \mathrm{mg} / \mathrm{L}$, hiệu suất xử lý đạt trên $80 \%$.

- Tại chế độ thí nghiệm 3, chu kỳ sục khí - ngừng sục khí là 110 phút/70 phút, với nồng độ COD đầu vào khoảng 1300 - 1600 $\mathrm{mg} / \mathrm{L}$ thì hiệu suất cao hơn đạt trên $85 \%$, nồng độ đầu ra tương đối ổn định trong khoảng $200 \mathrm{mg} / \mathrm{L}$.

Như vậy, chế độ sục khí không ảnh hưởng nhiều đến hiệu suất xử lý COD. Ở cả 3 chế độ đều cho hiệu suất xử lý đạt trên $80 \%$. Nồng độ đầu ra hầu hết trong khoảng 200 mg/L (đạt 10-TCVN 678:2006, loại B). Tuy nhiên chế độ 3 vẫn cho kết quả ổn định hơn cả.

\subsection{Hiệu quả xủ̉ lý Nito}

\subsubsection{Hiệu quả xủ lý $\mathrm{N}-\mathrm{NH}_{4}{ }^{+}$}

Ảnh hưởng của chu kỳ sục khí - ngừng sục khí đến hiệu suất xử lý $\mathrm{NH}_{4}^{+}$được thể hiện trong hình 3.

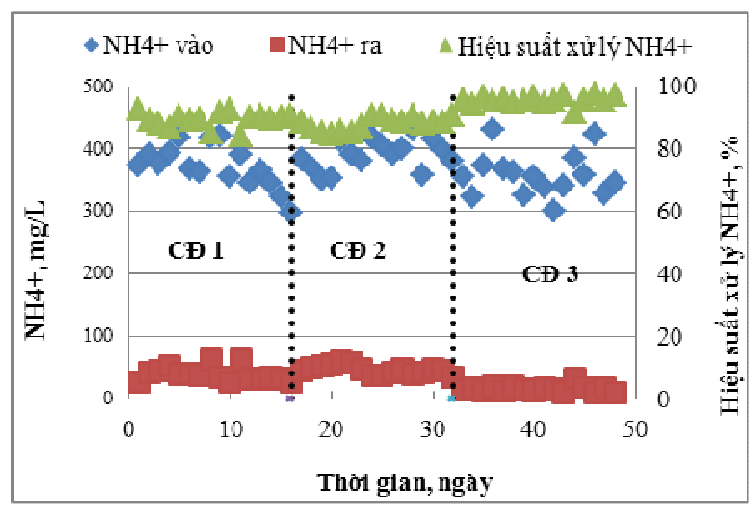

Hình 3. Anh hwởng của chế độ sục khí ngùng sục khí đến hiệu suất xử lý $\mathrm{NH}_{4}^{+}$

- Tại chế độ 1 và chế độ 2 , hiệu suất xử lý amoni đạt khoảng 85 - $90 \%$, nồng độ amoni đầu ra cao hơn so với chế độ 3 dao động trong khoảng 10 - 60 mg/L. Nguyên nhân là do thời gian sục khí ngắn hơn nên hiệu suất xử lý amoni ở chế độ 1 và chế độ 2 thấp hơn chế độ 3 .

- Tại chế độ 3, hiệu quả xử lý amoni tương đối cao trên $90 \%$. Nồng độ $\mathrm{NH}_{4}{ }^{+} \mathrm{ra}<$ $25 \mathrm{mg} / \mathrm{L}$.

Như vậy có thể nhận thấy thời sục khí ở chế độ thí nghiệm 3 là tương đối phù hợp để thực hiện quá trình nitrat hóa, hiệu suất xử lý amoni đều tốt, đạt trên $90 \%$.

\subsubsection{Sự chuyển hóa $\mathrm{NO}_{2}^{-}$và $\mathrm{NO}_{3}^{-}$}

Ảnh hưởng của chế độ sục khí - ngừng sục khí đến sự chuyển hóa $\mathrm{NO}_{2}^{-}$và $\mathrm{NO}_{3}^{-}$được thể hiện ở hình 4.

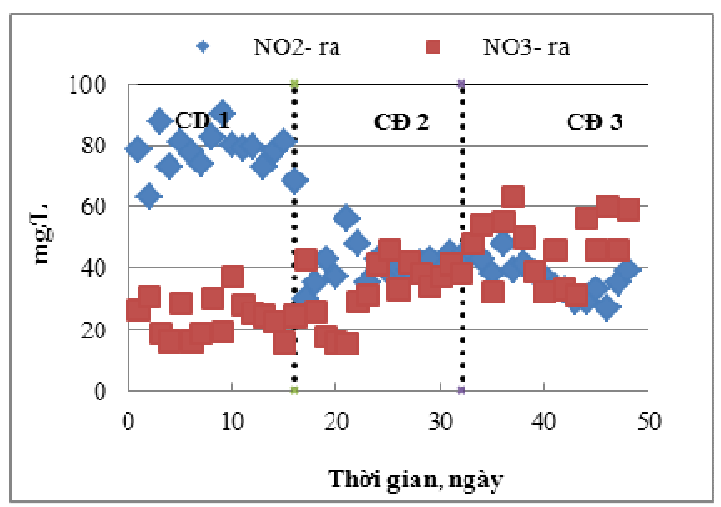

Hình 4: Anh hương của chế độ sục khí - ngùng sục khí đến sự chuyển hóa $\mathrm{NO}_{2}^{-}$và $\mathrm{NO}_{3}^{-}$ 
Tại chế độ 1 thì nồng độ $\mathrm{NO}_{2}^{-}$đầu ra rất cao, dao động trong khoảng 60 - 90 mg/L, nguyên nhân là do thời gian sục ngắn và thời gian ngừng sục lâu. Ở chế độ 2 , nồng độ $\mathrm{NO}_{2}{ }^{-}$ ra có giảm hơn so với chế độ 1 nhưng vẫn cao hơn so với chế độ 3 do tăng thời gian sục khí nhưng vẫn để thời gian ngừng sục lâu. Việc tăng thời gian sục khí lên 110 phút và giảm thời gian ngừng sục khí xuống còn 70 phút làm cho nồng độ $\mathrm{NO}_{2}^{-}$trong nước đầu ra là thấp nhất trong ba chế độ thí nghiệm, khoảng 20 - $50 \mathrm{mg} / \mathrm{L}$.

Tuy nhiên, thời gian ngừng sục khí ở chế độ 1 và chế độ 2 dài hơn nên khả năng khử nitrat tốt hơn chế độ 3 có thời gian ngừng sục khí ngắn nên quá trình khử nitrat không đủ để thực hiện hết, vì thế tại chế độ 3 NO3đầu ra là cao nhất hầu hết đều $>30 \mathrm{mg} / \mathrm{L}$.

Từ những nhận xét ở trên có thể thấy chế độ sục khí - ngừng sục khí ảnh hưởng rõ rệt đến sự chuyển hóa nitrat và nitrit trong hệ.

\subsubsection{Hiệu quả xủ lý $T-N$}

Ảnh hưởng của chế độ sục khí - ngừng sục khí đến hiệu quả xử lý tổng nitơ được thể hiện ở hình 5.

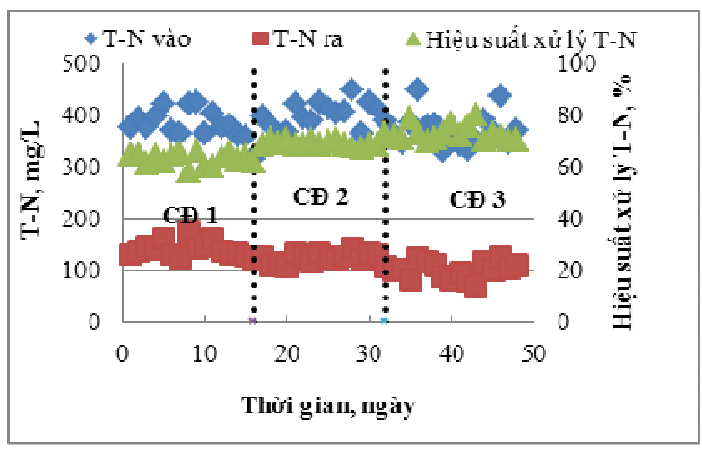

Hình 5. Anh hưởng của chế độ sục khí ngùng sục khí đến hiệu quả xử lý $T-N$

Xử lý $\mathrm{T}-\mathrm{N}$ là mục đích chính của nghiên cứu này, lượng $\mathrm{N}$ đầu vào của nước thải sau Biogas rất cao thường khoảng 350 $\mathrm{mg} / \mathrm{L}$ có những ngày có thể lên tới 450 - 500 $\mathrm{mg} / \mathrm{L}$. Thời gian sục khí - ngừng sục khí ảnh hưởng rất lớn đến hiệu suất loại bỏ $\mathrm{N}$. Qua đồ thị trên ta thấy, ở chế độ 1 thì hiệu suất của hệ thống chỉ đạt khoảng 60 - 65\%, nồng độ tổng
$\mathrm{N}$ đầu ra còn cao khoảng 135 - 170 mg/L. Tới chế độ 2 thì hiệu suất xử lý $\mathrm{T}-\mathrm{N}$ đã đạt tới khoảng $65-70 \%$ và sang chế độ 3 thì hiệu suất xử lý T-N đã đạt tới khoảng $75-80 \%$, nồng độ $\mathrm{T}-\mathrm{N}$ đầu ra dưới $120 \mathrm{mg} / \mathrm{L}$ (đạt 10TCN 678:2006, loại B). Như vậy có thể nhận thấy, tỷ lệ thời gian sục khí - ngừng sục khí ở chế độ 3 là đạt hiệu quả xử lý nitơ cao nhất.

\subsection{Anh huơng cua tải luọng COD, tải lựng T-N đến hiệu suất xư lý COD, $T-N$}

Các thí nghiệm đánh giá ảnh hưởng của tải lượng $\mathrm{COD}$, tải lượng $\mathrm{T}-\mathrm{N}$ đến hiệu quả xử lý $\mathrm{COD}$ và $\mathrm{T}-\mathrm{N}$ trong nước thải chăn nuôi được nghiên cứu ở 2 chế độ:

Chế độ 1 (CĐ1): Q = 26 L/ngày, thời gian lưu là 1,5 ngày.

Chế độ 2 (CĐ2): Q = 19,2 L/ngày, thời gian lưu là 2 ngày.

Duy trì chế độ sục khí - ngừng sục khí 110 phút/ 70 phút.

3.4.1. Anh hương của tải lương $C O D$ đến hiệu quả xủ lý COD

Ảnh hưởng của tải lượng COD đến hiệu suất xử lý $\mathrm{COD}$ được thể hiện ở hình 6 .

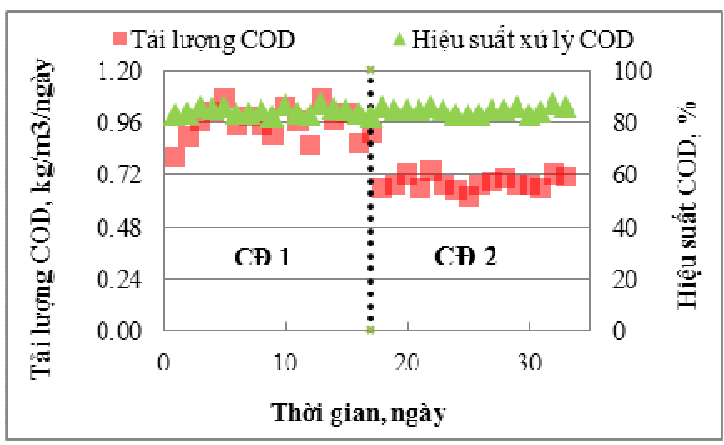

Hình 6. Anh hwởng của tải lượng COD đến hiệu suất xử lý COD

Qua hình 6 ta nhận thấy, trong quá trình nghiên cứu thay đổi tải lượng từ $0,6 \quad-1,1$ $\mathrm{kg} / \mathrm{m}^{3} /$ ngày thì hiệu suất xử lý COD không có sự thay đổi lớn, hầu hết đều đạt trên $80 \%$.

Hiệu suất COD không bị ảnh hưởng nhiều bởi tải lượng đầu vào, điều này là do khoảng biến động tải lượng COD nghiên cứu tương đối 
nhỏ và chất hữu cơ trong nước thải chăn nuôi lợn là chất dễ phân hủy sinh học.

3.4.2. Anh hương của tải lượng $T-N$ đến hiệu suất xử lý $T-N$

Ảnh hưởng của tải lượng T-N đến hiệu quả xử lý T-N được thể hiện trên hình 7 .

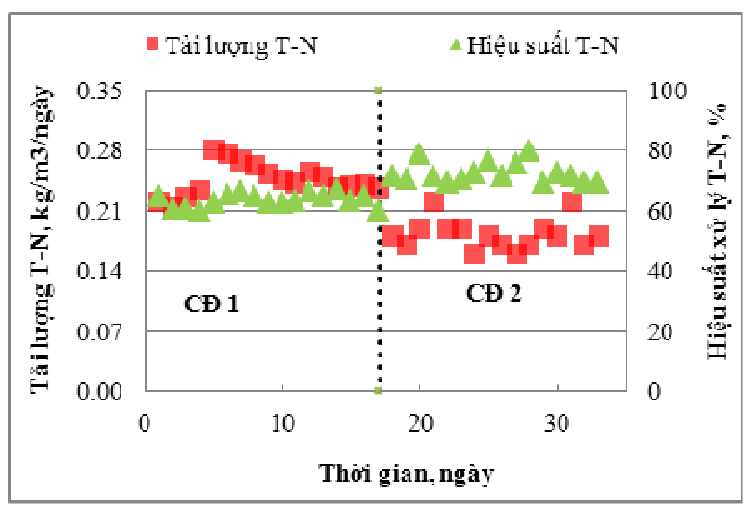

Hình 7. Anh hương của tải lương T-N đến hiệu quả xủ lý $T-N$

Trong nghiên cứu này tải lượng $\mathrm{T}-\mathrm{N}$ dao động trong khoảng 0,14 - 0,28 $\mathrm{kg} / \mathrm{m}^{3} / \mathrm{ngày}$. Thông thường, để xử lý amoni bằng phương pháp lọc sinh học cần duy trì tải lượng amoni ở mức dưới $0,2 \mathrm{~kg} / \mathrm{m}^{3} /$ ngày. Ở chế độ 1 , tải lượng $\mathrm{T}-\mathrm{N}$ có sự dao động trong khoảng $0,21-0,28 \mathrm{~kg} / \mathrm{m} 3 /$ ngày, hiệu suất xử lý T-N ở chế độ 1 thấp chỉ đạt khoảng 60 $65 \%$. Chế độ 2 , tải lượng $\mathrm{T}-\mathrm{N}$ duy trì trong khoảng $0,14-0,21 \mathrm{~kg} / \mathrm{m} 3 /$ ngày, hiệu suất đã được nâng lên ở khoảng $70-80 \%$. Kết quả này cho thấy, tải lượng $\mathrm{T}-\mathrm{N}$ đầu vào có ảnh hưởng rõ rệt đến hiệu suất xử lý $\mathrm{T}-\mathrm{N}$ và khoảng tải lượng thích hợp nằm trong chế độ thí nghiệm 2.

\section{Kết luận và kiến nghị Kết luận:}

* Về ảnh hưởng của chế độ sục khí tới hiệu quả xử lý COD, T-N

- Chế độ sục khí không ảnh hưởng nhiều đến hiệu quả xử lý COD. Hiệu quả xử lý COD ở cả 3 chế độ sục khí đạt trong khoảng $80-85 \%$ và khá ổn định. COD đầu ra hầu hết dao động khoảng 200 mg/L (đạt 10TCN 678:2006, loại B).

- Hiệu suất xử lý $\mathrm{N}$ đạt cao nhất ở chế độ 3 (sục khí - ngừng sục khí là 110 phút/70 phút) đạt khoảng $75-80 \%$. T-N đầu ra khoảng $150 \mathrm{mg} / \mathrm{L}$, có khi xuống dưới 80 $\mathrm{mg} / \mathrm{L}$.

- Chế độ sục khí - ngừng sục khí là 110 phút/70 phút cho hiệu quả xử lý $\mathrm{COD}, \mathrm{T}-\mathrm{N}$ cao và ổn định nhất.

* Về ảnh hưởng của tải lượng COD, T$\mathrm{N}$ tới hiệu quả xử lý $\mathrm{COD}, \mathrm{T}-\mathrm{N}$

- Tải lượng COD hầu như không ảnh hưởng nhiều đến hiệu quả xử lý COD.

- Tải lượng T-N có sự ảnh hưởng rõ rệt đến hiệu suất loại bỏ T-N.

- Chế độ $2(\mathrm{Q}=19,2$ L/ngày, thời gian lưu là 2 ngày), tải lượng $\mathrm{T}-\mathrm{N}$ duy trì trong khoảng $0,14-0,21 \mathrm{~kg} / \mathrm{m} 3 /$ ngày, hiệu suất xử lý cao nhất, đạt khoảng 70 - 80\%.

\section{Kiến nghị:}

- Thực hiện tiếp các nghiên cứu để tìm ra chế độ thích hợp hơn cho hệ xử lý bằng phương pháp lọc sinh học ngập nước.

- Nghiên cứu thêm về khả năng xử lý SS, T-P của hệ lọc sinh học ngập nước đối với nước thải chăn nuôi lợn.

- Nghiên cứu, đưa ra công nghệ xử lý nước thải chăn nuôi thích hợp nhất và tiến hành áp dụng vào thực tế để góp phần xử lý chất thải chăn nuôi trong điều kiện của Việt Nam. 


\section{TÀI LIỆU THAM KHẢO}

1. Bộ Nông nghiệp và Phát triển nông thôn (2011). Báo cáo kết quả thực hiện 12 tháng năm 2011 ngành Nông nghiệp và Phát triển nông thôn. Trung tâm Tin học và Thống kê.

2. Lê Văn Khoa, Nguyễn Văn Cự, Bùi Thị Ngọc Dung, Lê Đức, Trần Khắc Hiệp, Cái Văn Tranh (2002). Phuoong pháp phân tích đất, nước, phân bón, cây trồng,. Nhà xuất bản Giáo dục.

3. Lê Công Nhất Phương (2009). Nghiên cưu ưng dụng nhóm vi khuẩn Anammox trong xủ lý nuớc thải nuôi heo. Luận án Tiến sĩ khoa học, Viện Môi trường và Tài nguyên, Trường Đại hoc Quốc Gia TP. Hồ Chí Minh.

4. Vũ Đình Tôn, Lại Thị Cúc, Nguyễn Văn Duy (2008). Đánh giá hiệu quả xủ lý chất thải bằng

bể biogas của một số trang trại chăn nuôi lợn vùng đồng bằng sông Hồng. Tạp chí Khoa học và Phát triển, Trường Đại học Nông nghiệp Hà Nội, số 6/2008.

5. Phùng Thị Vân, Phạm Sỹ Tiệp, Nguyễn Văn Lục, Nguyễn Giang Phúc Trịnh Quang (2005). Xây dưng mô hình chăn nuôi lợn trong nông hộ nhằm giảm thiểu ô nhiễm môi trương và nâng cao năng suất chăn nuôi. Tạp chí Chăn nuôi, Viện Chăn nuôi. 